\title{
Resilience in the Context of Informal Care giving: A Scoping Study
}

Authors:

Xiaohua Zhao, ${ }^{\mathrm{a}, \mathrm{b}}$,

Kyunghwa Lee ${ }^{\mathrm{b}, \mathrm{c}}$,

Janice Penrod ${ }^{\mathrm{b}}$,

Brenda L. Baney ${ }^{\mathrm{b}}$,

Jane R. Schubart ${ }^{\mathrm{d}}$

\section{Authors Note:}

${ }^{\text {a }}$ Suzhou Health College, Jiangsu Province, China

${ }^{b}$ College of Nursing, The Pennsylvania State

Univers ity, University Park, PA 16802 USA

${ }^{c}$ Kunsan College of Nursing, Jeollabuk-do, South

Korea

${ }^{\mathrm{d}}$ Departments of Surgery, Medicine, and Public

Health Sciences, The Pennsylvania State

University, College of Medicine, Hershey, PA 17033 USA

\section{Corresponding Author:}

Jane R. Schubart, Ph.D.

The Pennsylvania State University

College of Medicine

Department of Surgery

500 University Drive, H151

Hershey, PA 17033

Tel: (717) 531-1262

Fax: (717) 531-4464

Email: jschubart@hmc.psu.edu

\section{Abstract}

To examine the state of the science surrounding the concept of resilience as used in the context of informal caregiving. This study was designed as a scoping study consisting of a five stage process to investigate the extent, range and nature of research activity related to resilience and informal caregiving. Data consisted of peer-reviewed articles in the scientific literature. One database (PubMed) was determined to be most relevant to this study. Search terms included "family caregiver and resilience" or "informal caregiver and resilience." The date of publication was restricted from January 2003 to May 2014. Forty articles were included in the analysis. The analytic technique included developing a codebook, coding all articles us ing 13 categories of interest, and compiling descriptive characteristics attributed to the concept of resilience. Content and thematic analytic techniques were used. The initial search yielded 178 citations, of which 137 were read by multiple team members. The final data set included 40 articles that reported 41 studies. Twenty-two studies applied quantitative approaches, 5 were purely qualitative work, 7 used a mixed methods approach and 7 were reviews. Resilience was found to be a concept relevant to multiple disciplinary perspectives and interdisciplinary co-authorship was prevalent in the literature. Typically, the context of caregiving was framed by health conditions that impact the care recipient's capability to perform the activities associated with daily living. Spousal caregivers were the most dominant relationship studied, followed by parental relationship. Age of caregivers care recipients varied widely. Studies conceptualized resilience in various ways, with 19 using theoretical or conceptual framework to various degrees; only 12 reported the measures of resilience. Across studies, resilience emerged as a protective factor for the burdens of caregiving. This scoping study revealed that the concept of resilience may have important implications in understanding the complex trajectories of end-of-life caregiving.

Keywords : informal caregiving; resilience; review; scoping 


\section{Resilience in the Context of Informal Care giving: A Scoping Study}

\section{Introduction/B ackground}

Scoping studies were described by Arksey and O'Mally (2005). In this framework, a five stage process is applied in order to investigate the extent, range and nature of research activity in a focused area. As described by Davis et al. (2009), a scoping study is a substantive, conceptual approach to extract the essence of a diverse body of evidence. The aim of this research study was to examine the concept of resilience of informal caregivers across a diverse body of relevant disciplines and synthesize the findings to provide meaning.

\subsection{Identifying the Research Question}

An interdisciplinary group of researchers interested in end-of-life caregiving were struck by patterns of responses to adversity exhibited by caregivers in a large prospective qualitative study [NIH/NINR 1R01NR010127, PI: J. Penrod]. The theoretical model derived in that work describes the phases of caregiving across protracted end of life trajectories (Penrod, Hupcey, Baney, \& Loeb, 2011). Across all phases of the end-of-life caregiving trajectory, caregivers centered on achieving a sense of normal or a steady state in the face of new adversities (Penrod, Hupcey, Shipley, Loeb, \& Baney, 2012). This study found that there were similar challenges or adversities faced by caregivers (e.g., increased caregiving demand due to functional decline or changes in the treatment regimen as disease advanced) with similar resources upon which to draw. Yet, despite facing similar adversities/resources in the caregiving context, some caregivers were able to achieve a state of "normal" rather quickly, while for others, a steady state seemed elusive.

Exemplars included caregivers who described acknowledging an adversity, then taking it in stride with confidence. They articulated the new challenge and went on to describe what they considered the best course of action. These caregivers proceeded to enact their plan, adjusting strategies as needed to accommodate changes in caregiving demands or approaches. They did not look back; rather they focused on the present and near future.
In contrast, other caregivers facing very similar challenges with similar resources available responded quite differently. These caregivers acknowledged the adversity or challenge in the present, then quickly reverted to relating experiences in the past, recounting difficulties and perceived failures. These caregivers' descriptions were fraught with "what if" s" instead of "can do's". At the same time, the team discovered work on resilience in the context of bereavement (Bonanno, 2010). Our investigation began by performing a template comparison (Morse \& Penrod, 1999) of the theoretical framing of bereavement formulated by Bonanno with the derived phase Inventing Normal (the after-death phase of caregiving). This work revealed the potential utility of the concept of resilience for understanding varied patterns of response to adversity among caregivers (Penrod, Baney, \& McGhan, 2012). The purpose of this scoping study was to examine the state of the science surrounding the concept of resilience as used in the context of informal caregiving. The research question was: How does the multidisciplinary literature apply the concept of resilience in the context of caregiving?

\subsection{Identifying Relevant Studies}

In order to scope the state of the science surrounding the concept of resilience as used in the context of informal caregiving, data consisted of peer-reviewed articles in the scientific literature. One database (PubMed) was determined to be most relevant to this scoping study. Search terms included "family caregiver and resilience" or "informal caregiver and resilience." The date of publication was restricted from January 2003 to May 2014 to capture the most recent and relevant theoretical attributes of resilience. No other restrictions were used in the search parameters. The initial search yielded 178 citations. Of these, twenty articles could not be retrieved through a large university library system and two were not available in English language; therefore, these were excluded. Abstracts were retrieved and reviewed for the remaining 156 articles. In this process, 19 articles were deleted because resilience was used 


\section{Resilience in the Context of Informal Care giving: A Scoping Study}

only as a key word without addressing the concept in the abstract.

\subsection{Study Selection}

Following this delimitation, full text articles $(\mathrm{N}=137)$ were read by multiple team members. In the first round of delimitation by the team, an additional 23 artic les were deleted from the dataset as these articles did not address informal or family caregivers. Two papers reported on the same study (with similar insights), so only one of these articles was retained $(\mathrm{N}=113)$. A second round of delimitation narrowed the dataset more precisely by excluding articles that failed to address informal or family caregiving with any depth (e.g., included caregivers in a mixed sample) or examined resilience superficially (e.g., used the term in the discussion or as a potential topic for further research). The team met to review the second round of delimitation and reached consensus to exclude 73 additional articles. Through this rigorous review process, the final data set consisted of 40 articles that addressed resilience and informal caregiving from multiple disciplinary perspectives. One article retained in the dataset reported on two distinct studies of resilience and informal caregiving; therefore, the final dataset includes 40 articles and 41 reported studies (Table I).

\subsection{Charting the Data}

Techniques of content and thematic analysis were used. Five articles were selected randomly from the dataset. The full team read and re-read this sub-set to determine an initial coding schema. During a team meeting, members contributed insights that were considered relevant to understanding the concept of resilience as used in the context of informalfamily caregiving. A codebook was developed by the team and another sub-set of five articles were selected randomly and coded by all members in order to evaluate the clarity/precision of the codebook. In a subsequent team meeting the coding was reviewed. Minimal discrepancies in coding were identified and discussed. Code definitions were refined and collapsed into categories. Primary responsibility for coding was assigned to two team members. Inter-rater reliability was assessed at the completion of coding ten articles and results were discussed at each weekly team meeting. There were marginal discrepancies in coding discovered through this process. When coding discrepancies occurred, the team discussed the appropriate code and the coded data were revised. This process continued throughout the period during which coding occurred, enhancing the reliability of application of the coding schema.

\subsection{Collating and Summarizing}

All of the articles were coded using the final 13 categories of interest and the data were segmented to permit further analysis. An Excel spreadsheet was used to format the matrix (i.e., columns were labeled with codes; rows referred to articles). This matrix provided an accessible visual format for subsequent analysis. Analys is proceeded through a detailed examination of coded data for each code. Analytic techniques of qualitative description described by Sandelowski (2000) were applied. Content analysis was used to develop descriptive characteristics of each category in the coding schema. Since the investigation was conceptually focused, the team also applied thematic analys is to develop a deeper conceptual interpretation of the data. Team members worked independently and as a group through the process of analysis, discussing preliminary findings during weekly team meetings. Through this process, the team compiled the descriptive characteristics attributed to the concept of resilience in informal caregivers. This analytic technique met the needs of this exploratory scoping study, as the inquiry focused on understanding the state of the literature surrounding resilience in informal caregivers.

\subsection{Reporting Results \\ 1.6.1 Discipline}

Resilience is a concept that is relevant to multiple disciplinary perspectives and interdisciplinary coauthorship was prevalent in the literature. In this study, the disciplinary focus of the article was determined by evaluating the targeted audience of the journal. This decision was predicated on the notion that, in order to understand the reach of dissemination of the study, targeted readership was 
Medical Research Archives, Volume 4, Issue 6.

\section{Resilience in the Context of Informal Care giving: A Scoping Study}

the most reliable indicator of permeation of the scientific community.

Demonstrating the multidisciplinary appeal of the concept of resilience and caregiving, 60\% (N=24) of the 40 articles reviewed were published in journals that target a multidisciplinary readership. As shown in Table II below, the largest segment in the multidisciplinary literature was in gerontology $(\mathrm{N}=7 ; 29 \%$ of the multidisciplinary segment), followed by palliative care $(\mathrm{N}=3 ; 12.5 \%$ of the multidisciplinary segment), and family $(\mathrm{N}=3$; $12.5 \%$ of the multidisciplinary segment). The remaining articles classified as multidisciplinary $(\mathrm{N}=11 ; 45.8 \%$ of the multidisciplinary segment) were published in a wide variety of journals with a specialty focus (e.g., Alzheimer's disease, rehabilitation).

Among the discipline-specific literature $(\mathrm{N}=16)$, $50 \%$ of the articles $(\mathrm{N}=8)$ were published in journals targeting psychology or psychiatry. Of these, six articles (75\% of the psychology segment) were in journals with a broad targeted readership, without a specific specialty focus. The remaining two articles were in specialty focused journals in family and geriatrics. Nursing journals published almost as many articles focused on resilience and caregiving $(\mathrm{N}=7)$. As was evident in the psychology segment, the majority of the articles in nursing literature were published in journals with a broad disciplinary scope $(\mathrm{N}=4 ; 57 \%$ of the nursing segment); two were in psychiatric/mental health specialty journals, and one was published in an older adult specialty journal. The only other specific disciplinary focus was in social work, where one article was published in a gerontologyfocused journal.

\subsubsection{Context}

Caregiving may be conceptualized broadly as helping another person. Typically, the context of caregiving is framed by health conditions that impact the care recipient's capability to perform the activities associated with everyday life. In this study, context was defined as the situation that prompted a need for caregiving (Table III). In most cases, the context of caregiving was marked by a chronic health condition $(\mathrm{N}=31 ; 76 \%)$; however, situations rooted in social and economic influences were also addressed $(\mathrm{N}=5 ; 12 \%)$. Upon the death of the care-recipient, informal caregivers adapt to a new way of life without the everyday demands of caring for another. This period of bereavement (or, living through a loss) is another significant context of the examination of resilience in this literature $(\mathrm{N}=5 ; 12 \%)$.

\subsubsection{Sample characteristics}

Caregiving relationship. The purpose of this category was to examine the extent of variation in the relationship between caregivers and care recipients in the context of resilience. Thirty-three articles reported discrete data regarding the relationship between caregiver and care recipient. Of these, 27 articles (82\%) described mixed samples; two included only spouses; two included child-caregivers; one included only parents; and one included only mothers.

In order to more fully examine the characteristics of caregiver relationships, the reported samples were combined and analyzed across studies (Table IV below). Using this combined data set $(\mathrm{N}=7525)$, spousal caregivers were the most dominant relationship studied $(\mathrm{N}=2365 ; 31.4 \%$ of reported samples) followed by parental relationship ( $\mathrm{N}=2141 ; 28.5 \%$ of reported samples). It was not surprising that within the spousal and parental subsets, studies reporting gender revealed a dominance of female caregivers $(\mathrm{N}=1035$ [80\%] to 259 [20\%] respectively). Other segments of relationships included: children of the care recipient $(\mathrm{N}=1068$; $14.2 \%)$; siblings $(\mathrm{N}=196 ; 2.6 \%)$. At less than $1 \%$ of the specified samples segments, grandparents $(\mathrm{N}=55)$; grandchildren $(\mathrm{N}=64)$; and friends $(\mathrm{N}=53)$ were specified. It is important to note that due to the lack of specificity in describing the relationship of caregiving dyads, 1582 subjects (21\% of total specified sample) were not included in this analysis of relationship.

Caregivers' age. While caregiving is often perceived to be a phenomenon associated with middle and later life; caregiving experiences are not exclusive to adulthood. In this categorical analysis, 
Medical Research Archives, Volume 4, Issue 6.

\section{Resilience in the Context of Informal Care giving: A Scoping Study}

the age of the caregivers were examined to explore the range of developmental phases addressed in the literature pertaining to resilience. Of the 35 articles reporting discrete studies $74 \%$ provided thorough reporting of sampling characteristics. Ten studies $(28.6 \%)$ reported the caregivers' mean age, SD and range; 11 studies $(31.4 \%)$ reported mean and SD; three studies $(8.6 \%)$ reported range and distribution; and two $(5.7 \%)$ reported mean and range. The remaining $26 \%$ of the sample of discrete study reports $(\mathrm{N}=35)$ did not report caregiver age characteristics adequately. Of these, three studies $(8.6 \%)$ only reported the mean age of caregivers; one study $(2.9 \%)$ reported a wide range of the age of caregivers (i.e., 22-65 years); and five studies $(14.3 \%)$ simply reported a caregiver status without mean, SD or range of age. More precise reporting (even in qualitative studies) would permit a deeper understanding of the characteristics of resilience expressed across the varied developmental phases represented in this body of work.

The mean age of caregivers indicates that the most frequently studied developmental phase was middle adulthood, with $50 \%$ of the articles addressing adult caregivers between the ages of 35-59 years. While the mean age of caregivers is of interest, the illustrated range ages of caregivers studied (Fig. 1) demonstrates a much more diverse sampling approach. For example, three studies exclusively addressed child-caregivers aged 11-18 years. Cassidy and colleagues (Cassidy, Giles, \& McLaughlin, 2014) report a study of 442 childcaregivers providing care to family members with a range of physical, developmental, and mental disabilities. Svanberg and colleagues (2010) studied 12 children whose parent had some form of dementia. Fraser and Pakenhan (2009) examined 44 children of parents with mental illness. These studies demonstrate that caregiving responsibilities extend beyond the adults within a family system and indicate that resilience is not a developmentally dependent construct.

Age care recipients. The recipients of care addressed in the data set ranged in age from "not yet born" (Nabors et al., 2013, p. 173) to adults in the ninth decade of life. The analysis of the age of care recipients was constrained by inadequate reporting. For example, only $46 \%$ of the study reports $(\mathrm{N}=35)$ described the care recipient sample thoroughly, including mean, $\mathrm{SD}$, range $(\mathrm{N}=8)$; mean and SD $(\mathrm{N}=5)$; and mean and range $(\mathrm{N}=3)$. The remaining $54 \%$ of the sample $(\mathrm{N}=19)$ reported only the range of age of care recipients or did not report descriptive findings regarding care recipients beyond the types of conditions for which care was required.

As illustrated in Fig. 2, 15 of 35 studies (43\%) reported the age of care recipients examined in the studies. While the range is broad across studies, among those studies reporting mean age of care recipients $(\mathrm{N}=16), 50 \%$ of the studies addressed care recipients who were under the age of 18 years. While the phenomenon of caregiving to older adult care recipients has been investigated thoroughly, the study of resilience among caregivers of older adults is less pronounced.

\section{Design}

Among the 41 reported studies, twenty-two (53.7\%) applied quantitative approaches. Of these, 15 were cross sectional descriptive studies; two tested an intervention; and five examined causal relationships between resilience and other factors longitudinally. Only five studies (14.6\%) were purely qualitative work. Mixed methods were used in seven of the studies (17\%); with six using a quantitative-qualitative approach and one applying a review-qualitative approach. In addition to the original research studies reported above, seven articles (17\%) were reviews. Of these, three articles used literature as data applying techniques of concept analysis, integrative review, and literature review.

\subsection{Theore tical/Conce ptual Frame work}

Nineteen articles included a theoretical or conceptual framework of resilience in differing degrees. Seven used resilience theory as a framework to guide the study. Three studies included variables related to resiliency, but did not use resilience as a framework. Six articles reported qualitative studies that linked resilience to an emergent theme. Three studies used the concept of 


\section{Resilience in the Context of Informal Care giving: A Scoping Study}

resilience to integrate findings across a program of research.

In the studies that used a formal theory of resilience to actually guide the study, two were based on the Resiliency Model of Family Stress, Adjustment and Adaptation (M. A. McCubbin \& McCubbin, 1993; Shin, Choi, Kim, \& Kim, 2010) and provided a description of the underlying model which considers how stress impacts the family system and how resilience factors affect both individual and family adaptation and well-being. The main conceptual components examined in Shin's study were family hardiness, problem-solving, coping, communication, social support, and skill seeking. Yeh et al. (2012) based their research questions on the same model, emphasizing family adaption to an illness stressor that affects family life, but they added other conceptual components. For example, "level of family appraisal" can help with family coping and adaptation by producing optimal problem solving (Yeh \& Bull, 2012, p. 119).

Bayat et al. (2007) based their study on Walsh's family resilience framework (2003) which builds on the work of McCubbin and colleagues (1983) and Patterson $(1988,2002)$. In this theoretical approach, the ecological and developmental perspectives are combined to conceptualize family functioning in a broader sociocultural context. Family functioning is examined from a family lifecycle perspective. This framework extends family stress, coping, and adaption by including the potential for personal and relational growth and transformation that comes out of adversity. Walsh emphasizes that family processes, risk and resilience may vary at different times, and observes that in fact most major stressors are a set of complex changing events. For some families who do well in a short-lived crisis, persistent or recurrent stressors may be too stressful. Gaugler et al. (2007) applied a variant of the multidimensional resilience model proposed by Bergeman and Wallace (1999) in their study of adolescent resilience. This model includes levels of perceived burden in relation to various levels of caregiving demands that are influenced by the context of care, status of care recipient, and individual and family/community resources.

Other studies were framed in terms of less specific resilience models. Wilks et al. (2008) refer to traditional models of moderation and mediation and use an adapted mediation model that asserts that the impact of perceived stress on caregiver resilience may be due to its effect on social support which in turn affects resilience. Leve et al. (2009) mentions resiliency theory as guiding the intervention in the ir study by emphasizes the role of family interactions in predicting resiliency outcomes in children.

In other studies, a resilience framework is not defined; however, variables related to resilience are specified. For example, Fraser (2009) used variables of mental health literacy, social connectedness, and coping strategies. Likew ise, Cassidy et al. (2014) mentions a "stress-coping" model (but not a specific model) and includes measures related to resilience but there is not a description of their fit with theory. Simpson et al. (2013) included variables that were consistent with the adaptive understanding of resilience and mentions that the results are consistent with resilience theory, but there is no specific theoretical framework. Sandler et al. (2013) refer to resilience theory underlying a program that will lead to changes in targeted risk; however, there is little description.

Six articles describe qualitative studies that linked resilience to an emergent theme. For example, Shuter et al. (2014) situated a grounded theory study in two models based on adaptation overtime, Kramer's Conceptual Model of Caregiver Adaption (1997) and the Cognitive-based Behavioural Conceptualisation of Complicated Grief (Boelen, van den Hout, \& van den Bout, 2006). Within this framework, resilience was identified as an intrinsic factor that bolstered the caregivers' adaptation to the decline of dementia. In a grounded theory study, Nabor et al. (2013) drew upon their own model, largely based on Walsh (2003), which depicts caregiver anxiety as influenced by the resilience variables of family hardiness and family functioning. Chen et al. (2009) mentions the Family 


\section{Resilience in the Context of Informal Care giving: A Scoping Study}

Adjustment and Adaption Responses model in the discussion; resilience is one of several themes in the results.

In three articles, the concept of resilience was used more broadly to integrate findings across a program of research. O'Rourke et al. (2010) mention that their findings about resilience support a stress process model of caregiving (Pearlin \& Skaff, 1995) — a model which includes contextual factors, primary stressors, illness-related factors, and intrapsychic factors that can mediate negative caregiver stress. Lim et al. (2011) based their study of resilience to urban poverty on a multi-level framework. A sub-set of articles were framed conceptually around shortened resilience scales.

This analysis of the theoretical framing of studies of resilience reveals the complexity of the concept. There are competing theoretical frameworks addressing resilience. Stress-coping models are related, but do not exclusively address the concept of resilience. Numerous quantitative studies have been conducted without an overarching theoretical framework. Qualitative work addressing resilience is somewhat limited, interpreting thematic findings as a reflection of the concept of resilience.

\subsection{Explicit Definitions}

The Merriam-Webster defines resilience as "the capability of a strained body to recover its size and shape after deformation caused especially by compressive stress" (Merriam-Webster, n. d.). As applied to human experience, resilience is a term used to describe when an individual overcomes adversity, withstands stress or bounces back from traumatic events. The research of resilience however, has been predominantly theoretical with lack of homogeneity in understanding, operationalizing, and measuring of the concept (Giesbrecht, Wolse, Crooks, \& Stajduhar, 2015; Ruiz-Robledillo, De Andres-Garcia, Perez-Blasco, Gonzalez-Bono, \& Moya-Albiol, 2014).

Rutter (2006) describes resilience as a positive outcome despite adversity while others argue that resilience is a pre-existing trait or characteristic that enables one to overcome adversity (Connor, 2006; Richardson, 2002). Resilience is also considered a dynamic process of adaptation that is not static or finite but a process of multi-dimensional constructs of thoughts, feelings, and behaviors (Dyer \& McGuinness, 1996; Luthar, Cicchetti, \& Becker, 2000; Polk, 1997; Rolland \& Walsh, 2006). Risk and protective factors influence the complex process that may be modifiable and bolstered by intervention (Bayat, 2007; Lin, Rong, \& Lee, 2013; Rosenberg, Baker, Syrjala, Back, \& Wolfe, 2013). Rosenberg and his colleagues developed an "integrative, comprehensive framework" of resilience factors for family members of children with cancer. The three categories of factors identified, (1) baseline characteristics, (2) processes that evolve over time, and (3) psychosocial outcomes.

Resilience requires a negative stimulus (risk) described as a stressful situation that many maintain must be significant and extreme (Turner, 2001; G. M. Wagnild \& Young, 1993). The risk may be an event, a hardship, or a burden that threatens the person's stability, viability, or development. For example, the physical and psychological demands of caring pose a risk to informal caregivers. Thus, resilience in caregivers is successful adaptation to a care situation while maintaining health and fulfilling the caregiving role (Giesbrecht et al., 2015; Lin et al., 2013; Nabors et al., 2013; Ruiz-Robledillo et al., 2014). This successful adaptation is not only influenced by individual factors and intrinsic resources (Shuter et al., 2014), but also by family and socioenvironmental factors (Giesbrecht et al., 2015; Lin et al., 2013; Luthar et al., 2000). Studies focused only on individual factors inadequately describe the concept of resilience because "environmental conditions help shape resilience by mitigating the negative effects of adversity" (Amzel et al., 2013). Resilience in caregiving is influenced by socioenvironmental factors such as access to social networks, education/knowledge/awareness, employment status, geographic location of residence, housing status and life-course stage (Giesbrecht et al., 2015; Ruiz-Robledillo et al., 2014). Additionally, the individual, family, and socio-environmental factors that contribute to 
Medical Research Archives, Volume 4, Issue 6.

\section{Resilience in the Context of Informal Care giving: A Scoping Study}

resilience are cultural dependent (Hernandez, Barrio, \& Yamada, 2013).

\subsection{Meas ure ment of Resilience}

Only twelve articles in the dataset reported measures of resilience, and 7 (58\%) of these used instruments based on the work of Wagnild and colleagues. The 25-item Resilience Scale (G. M. Wagnild \& Young, 1993; G. Wagnild \& Young, 1990) was used in four studies. Abbreviated forms of the Resilience Scale have been developed. The 14-item RS-14 (G. M. Wagnild \& Collins, 2009) was used in one study and the 15-item RS-15 (Neill \& Dias, 2001) in two studies. Another article, (Wilks \& Vonk, 2008) examined the psychometric properties of the RS-15 in a rigorous crosssectional survey design involving caregivers of person with dementia. These authors concluded that the "RS-15 is a sound measure of resilience, more convenient in its brevity that the longer RS without psychometric loss" (p. 148). In particular, the RS15 "provided an empirical perspective on their [subjects'] toughness from past adversity and ability to overcome future adversity" (Wilks, 2008a, p. 148).

Other measurement tools included the Brief Resilience Scale (Smith et al., 2008) used in two projects. (However, both of these studies were conducted/reported by one author.) Four other tools were reported in single studies: Dispositional Resilience Scale (Bartone, Ursano, Wright, \& Ingraham, 1989); Connor-Davidson Resilience Scale (Connor \& Davidson, 2003); and the Brief Resilience Coping Scale (Sinclair \& Wallston, 2004). These instruments are focused primarily on stress and coping processes.

\subsection{Conclusions Related to Resilience}

First, in order to understand how the concept of resilience was positioned in studies involving informal caregivers, the explicitly stated purpose and design of each study were analyzed. Then, data were categorized based on the design of the 41 reported studies. In 11 quantitative studies reviewed, resilience was positioned as the independent variable, either reducing negative or enhancing positive health outcomes. Similarly, resilience was considered as an influencing factor related to outcomes in four qualitative studies. Studies examining the effect of a reduction of negative health outcomes in resilience included the following dependent variables: parental distress (Lamis, Wilson, Tarantino, Lansford, \& Kaslow, 2014); burden (Chappell \& Dujela, 2008; Hernandez et al., 2013; Simpson \& Jones, 2013; Yeh \& Bull, 2012); depression (Fraser \& Pakenham, 2009; O'Rourke et al., 2010); emotional/behavioral difficulties (Fraser \& Pakenham, 2009); being overweight (Lim et al., 2011); perceived stress (Cassidy, 2013; Chappell \& Dujela, 2008; Ruiz-Robledillo et al, 2014); institutionalization for dementia care (Gaugler et al., 2007); caregiver anxiety (Nabors et al., 2013); and suicidal thoughts (O'Dwyer, Moyle, \& van Wyk, 2013). Studies that examined the effect of enhancing positive outcomes on resilience framed independent variables as benefit finding (Cassidy, 2013; Cassidy et al., 2014); life satisfaction (Cassidy et al., 2014; Chappell \& Dujela, 2008; Fraser \& Pakenham, 2009); positive mental health (Cassidy et al., 2014); positive affect

(Simpson \& Jones, 2013); and adolescent adjustment (Shin et al., 2010).

In eight studies, resilience is positioned as the outcome variable (dependent variable). These studies explored independent variables that influenced resilience including risk factors and protective factors. Risk factors include caregiver burden (Bekhet, Johnson, \& Zauszniewski, 2012; Zauszniewski, Bekhet, \& Suresky, 2009), stress (Wilks, 2008b), ,bereavement (Bonanno, Moskowitz, Papa, \& Folkman, 2005) and Alzheimer's aggression (Wilks, Little, Gough, \& Spurlock, 2011). Protective factors include positive cognitions (Bekhet et al., 2012; Zauszniewski et al., 2009), culture function (Eggerman \& Panter-Brick, 2010), family and social support (Wilks, 2008b; Wilks \& Croom, 2008). All of the articles that examined resilience as an outcome assert that resilience is malleable. Resilience may be improved or protected by modifying risk (e.g., reducing stress) or enhancing protective factors (e.g., providing psycho educational support). 


\section{Resilience in the Context of Informal Care giving: A Scoping Study}

The analysis revealed how each study conceptualized resilience in order to categorize the study's contribution to theory development, understanding of conceptual attributes or interventions designed to alter the state of resilience. Insights derived through observational studies and review articles are described below.

\subsection{Observational Studies}

Observational studies focus on naturally occurring variables in a given context. Observational studies may be qualitative or quantitative and may be cross-sectional or longitudinal. Thematic analys is of the conclusions derived through observational studies revealed that resilience was conceptualized as both an individual and group (e.g., family) trait. For example, in a grounded theory study of grief and quality of life for caregivers of people with dementia, Shuter, Beattie, and Edwards (2014) described resilience as an intrinsic psychological resource that influenced the degree of distress after the death of the care recipient. In a study of rehabilitation of youth with spinal cord injury, House and colleagues (2009) found that caregivers perceived personal resilience, an intrinsic factor involving the care recipient's outlook on life postinjury and not feeling a victim as an important factors in successful rehabilitation. In mixed method study, Rosenberg and colleagues (2013) developed a conceptual framework of resilience that describes baseline characteristics of the individual that are influenced by communication and health care provider interactions.

Others have asserted that resilience may be manifest by the family unit (not individuals). For example, Chen and Boore (2009) studied family carers' experiences and needs while caring for a relative who has a spinal cord injury and concluded that family resilience can be achieved if the family (as a unit) can deal with the challenges and have a basis of competent functioning. Nabors et al. (2013) viewed resilience in relation to family hardiness and family functioning, which were related to lower caregiver state anxiety. Similarly, in a study of adolescents' adjustment to divorce in Korean families, resilience was the outcome variable, framed as family hardiness and family communication (Shin et al., 2010).

In contrast to studies of the family unit, when the care recipient/caregiver dyad was studied, resilience was found to be incongruent. Hall and colleagues (Hall, Cote, McBean, \& Purden, 2012) described the experiences of patients with pulmonary arterial hypertension who required an uninterruptable continuous intravenous infusion and their support persons. In the descriptive account of living with this high-tech treatment regimen, patients demonstrated characteristics of resilience; however, support persons did not. In contrast to the patient experience, caregivers face the onerous responsibility of managing lifesustaining care for a loved one; a lack of targeted skill-mastery sessions in support of their role; and a lack of social support. The authors posited that these experiential influences contributed to the dichotomous sense of resilience: while patients felt confident and well-supported in treatment, the caregivers did not.

Socio-cultural variables were identified as influential factors on resilience. Cultural values and beliefs were interpreted as posing either a positive or negative effect on resilience in the context of war ravaged Afghanistan (Eggerman \& PanterBrick, 2010). For example, some cultural values instill hope and foster resilience, while other values may foster a sense of entrapment, thus diminishing resilience. Giesbrecht and colleagues (2015) used ethnographic approaches to examine the socioenvironmental factors that facilitate resilience among family caregivers providing palliative care in Canada. Socio-environmental factors that were interpreted as facilitators of resilience included: access to social networks,

education/know ledge/awareness of services, employment status, housing, geographic location and life course stage. Broadly, the influence of social support was described as a protective factor. For example, in a study of caregiver suic ide during the protracted care of a person with dementia (O'Dwyer et al., 2013), social support was identified as an important protective factor. Similarly, Giesbricht and colleagues describe social 


\section{Resilience in the Context of Informal Care giving: A Scoping Study}

support or a network of strong interpersonal relationships as an important factor in building resilience.

Resilience has been linked to processes of coping and adaptation. Giesbrecht and colleagues (2015) framed resilience as the caregivers' adaptation to changing care demands with a positive expression of peace and contentment, without excessive burden or burn-out. Shuter, Beattie and Edwards (2014) viewed resilience as the capacity to deal with the burden of caregiving for a person with dementia over time. Characteristics of both caregiver and care recipient and use of resources were deemed important to such adaptation. Svanberg and colleagues (2010) regarded resilience as adapting to stress while promoting pride and independence among children caring for parents with dementia.

In another study describing resilience as mastering one's surroundings and self-efficacy, environmental factors such as social networks were explored. Education was shown to have a positive impact on caregivers' capacity for resilience (Giesbrecht et al., 2015). In studies of parents as caregivers (Sandler et al., 2013), a supportive group environment to help caregivers acquire and use positive parenting skills was found to contribute to resilience (defined in terms of successful adaptation).

Coping strategies, for caregivers of family members with mental illness, (Bull, 2014) to bolster psychological well-being included drawing on past life experiences, nourishing self, spirituality, and seeking information about the care recipient's condition (dementia). Dwyer, Moyle, and Wyk (2013, p. 759) asserted that the frequent use of practical coping was "the key to resilience" among participants in a study of suicidality among caregivers of people with dementia.

As authors discuss findings, several recommendations imply that resilience is malleable and could be responsive to intervention. For example, House and colleagues (2009) suggested that the provision of resources to young patients with spinal cord injury could foster resilience and improve rehabilitation outcomes. Shuter, Beattie, and Edwards (2014) recommend further exploration of initiatives that promote personal growth and improve caregiving resilience among those caring for a person with dementia.

The beneficial attributes or outcomes of resilience have been well documented. Resilience (viewed as a way of coping with and adapting to stress) was positively correlated with high levels of social interaction and social support (Ruiz-Robledillo et al., 2014). Resilience defined in terms of ability to see beyond an immediate stressful experience, and in that context high levels of hopefulness relate to this ability (Hernandez et al., 2013). Resilience was correlated with benefit finding (Cassidy, 2013; Cassidy et al., 2014), positive affect (Simpson \& Jones, 2013), and optimism, and self-efficacy (Cassidy, 2013). In another study of the predicted benefits of resilience factors, social connectedness was associated with caregiver adjustment, but mental health literacy was not (Fraser \& Pakenham, 2009). Among caregivers whose spouses have Alzheimer disease, those with psychological resilience (i.e., perceived control) had fewer depressive symptoms. Among caregivers with heavy caregiving demands, resilience emerged as the only significant predictor of three outcomes: burden, life satisfaction, and perceived stress (Chappell \& Dujela, 2008), and caregivers characterized has having high-resilience were less likely to institutionalize their care recipients (Gaugler et al., 2007). The most consistent association reported across studies was that of social support and resilience. Cause and effect is less clear; for example, one study pointed out social support may mediate an association between resilience and health (self-reported or biologic markers) (Ruiz-Robledillo et al., 2014) in that greater resilience enables a person to effectively seek social support (Lamis et al., 2014).

\subsection{Review}

Since review articles hold the potential to contribute to clarification of conceptual attributes, this sub-set of articles were analyzed to determine how the integration of what is known or synthesis 


\section{Resilience in the Context of Informal Care giving: A Scoping Study}

of new knowledge was advanced based on extant findings. In addition to the original research studies reported above, seven articles $(17 \%)$ were reviews. Of these, three articles used literature as data applying techniques of concept analysis, integrative review, and literature review. Lin, Rong, and Lee (2013) concept analysis applied methods described by Walker and Avant to examine the concept of resilience. Using integrative review techniques, Zauszniewski and Bekhet (2010) described resilience in adult family members of persons with serious mental illness. Finally, Harmell and colleagues (2011) examined a decade of professional literature to document the domains of resilience and related health outcomes among caregivers of people with dementia. These descriptive studies integrated what was known into new perspectives or ways of understanding; however were not a synthesis of new knowledge.

The other four review articles focused on the synthesis of new knowledge as the literature was used as a basis for recommending intervention or treatment. Amzel and colleagues (2013) reviewed literature to advocate for increasing the scope of interventions for children with HIV based on an ecological model; that is, they argue that interventions designed to promote resilience must extend beyond the individual into families and communities. Zhang, El-Jawahri, and Prigerson (2006) described resilience as a factor to be considered when targeting supportive bereavement services (i.e., those with higher resilience benefit less from supportive care during bereavement). Leve, Fisher, and Chamberlain (2009) described a conceptual framework positioning resilience as a mechanism to guide intervention for children exposed to adversity and summarized the effectiveness of a multidimensional treatment program promoting resilience in at-risk children examined in a program of research. Sandler and colleagues (Sandler et al., 2013) described an effective intervention for child bereavement based on a contextual resilience framework. This sub-set of literature indicates that these authors have judged the literature to be substantive enough to warrant intervention implications (an indicator of a rather robust state of the science).

\section{Discussion}

Across studies, quantitative and qualitative, resilience emerges as a protective factor for the burdens of caregiving; however, only 19 studies included a theoretical or conceptual model of resilience. Typically, qualitative studies are used to derive theory of varying types or levels of abstraction. In this dataset, only five studies $(14.6 \%)$ were purely qualitative work, implying that limited attention has been devoted to developing the conceptual or theoretical understanding of resilience among caregivers from a lived experience perspective. The methodological approach used in qualitative design contributes to the nature of the findings or the product of the research. For example, exploratory or descriptive qualitative methods aim to provide a descriptive account of the concept of resilience in a given context. Description is considered the lowest level or type of qualitatively-derived theory (Morse, 1997, pp. 163-188).

Resilience was found to be an influencing factor that reduces negative outcomes and enhances positive outcomes. But, resilience was also examined as outcome itself and found to be malleable, suggesting the need for direct interventions. Resilience has clear benefits to both caregivers and their care recipients. The context of the articles included in this scoping study were largely (but not exclusively) in the setting of caregiving framed by a health condition, including the period of bereavement. Spousal and parental relationships were predominant, but also not exclusive. Likewise, while those in middle adulthood were the most common group, caregivers represented a diverse age range. Thus, caregiving and resilience are not constructs unique to a single developmental group or even unique to health. This suggests that the potential impact of improved understanding of resilience is far reaching. The scoping study uncovered a breadth of disciplines publishing on the topic, yet adequate theoretical underpinnings were too often lacking.

\section{$4 . \quad$ Conclusion}

This scoping study revealed that the concept of resilience may have important implications in 
Medical Research Archives, Volume 4, Issue 6.

\section{Resilience in the Context of Informal Care giving: A Scoping Study}

understanding the complex trajectories of end-oflife caregiving. Further research is necessary to reveal if nurses could evaluate or assess resilience in order to better plan supportive care across protracted caregiving trajectories. It is known that caregiving in advanced illness is a long and difficult journey, fraught with challenges and adversities as the care recipient progresses toward death, and that caregivers risk deleterious effects in bio- psycho- and social spheres. Interventions designed to bolster resilience could help caregivers thrive in the face of adversity. 


\section{Resilience in the Context of Informal Care giving: A Scoping Study}

\section{References}

Amzel, A., Toska, E., Lovich, R., Widyono, M., Patel, T., Foti, C., . . . Children. (2013). Promoting a combination approach to paediatric HIV psychosocial support. AIDS, 27 Suppl 2, S147-157. [PubMed: 24361624]

Arskey, H., \& O'Malley, L. (2005). Scoping studies: towards a methodological framework. International Journal of Social Research Methodology Theory \& Practice, 8, 19-32. DOI:10.1080/1364557032000119616

Bartone, P. T., Ursano, R. J., Wright, K. M., \& Ingraham, L. H. (1989). The impact of a military air disaster on the health of assistance workers. A prospective study. The Journal of Nervous and Mental Disease, 177(6), 317-328. [PubMed: 2723619]

Bayat, M. (2007). Evidence of resilience in families of children with autism. Journal of Intellectual Disabilility Research: JIDR, 51(Pt 9), 702-714. [PubMed: 17845239]

Bekhet, A. K., Johnson, N. L., \& Zauszniewski, J. A. (2012). Effects on resilience of caregivers of persons with autism spectrum dis order: the role of positive cognitions. Journal of the American Psychiatric Nurses Association, 18(6), 337-344. [PubMed: 23139377]

Bergeman, C. S., \& Wallace, K. A. (1999). Resiliency in later life. In T. L. Whitman, T. V. Merluzzi \& R. D. White (Eds.), Life-span Perspectives on Health and Illness (pp. 207-225). Mahwah, NJ: Erlbaum.

Boelen, P. A., van den Hout, M., \& van den Bout, J. (2006). A cognitive-behavioural conceptualisation of complicated grief. Clinical Psychology: Science and Practice, 13(2), 109-128. DOI: 10.1111/j.1468-2850.2006.00013.x

Bonanno, G. A. (2010). The Other Side of Sadness: What the New Science of Bereavement Tells us About Life After Loss. New York, NY: Basic Books.

Bonanno, G. A., Moskowitz, J. T., Papa, A., \& Folkman, S. (2005). Resilience to loss in bereaved spouses, bereaved parents, and bereaved gay men. Journal of Personality and Social Psychology, 88(5), 827-843. [PubMed: 15898878]
Bull, M. J. (2014). Strategies for sustaining self used by family caregivers for older adults with dementia. Journal of Holistic Nursing: Official Journal of the American Holistic Nurses' Association, 32(2), 127-135. [PubMed: 24227181] Cassidy, T. (2013). Benefit finding through caring: the cancer caregiver experience. Psychology \& Health, 28(3), 250-266. [PubMed: 22928621]

Cassidy, T., Giles, M., \& McLaughlin, M. (2014). Benefit finding and resilience in child caregivers. British Journal of Health Psychology, 19(3), 606618. [PubMed: 23869796]

Chappell, N. L., \& Dujela, C. (2008). Caregiving: predicting at-risk status. Canadian Journal of Aging, 27(2), 169-179. [PubMed: 18845512]

Chen, H. Y., \& Boore, J. R. (2009). Living with a relative who has a spinal cord injury: a grounded theory approach. Journal of Clinical Nursing, 18(2), 174-182. [PubMed: 19120747]

Connor, K. M. (2006). Assessment of resilience in the aftermath of trauma. The Journal of Clinical Psychiatry, 67 Suppl 2, 46-49. [PubMed: 16602815]

Connor, K. M., \& Davidson, J. R. (2003). Development of a new resilience scale: the ConnorDavidson Resilience Scale (CD-RISC). Depression and Anxiety, 18(2), 76-82. [PubMed: 12964174]

Davis, K., Drey, N., \& Gould, D. (2009). What are scoping studies? A review of the nursing literature. International Journal of Nursing Studies, 46(10), 1386-1400. [PubMed: 19328488]

Dyer, J. G., \& McGuinness, T. M. (1996). Resilience: analysis of the concept. Archives of Psychiatric Nursing, 10(5), 276-282. [PubMed: 8897710]

Eggerman, M., \& Panter-Brick, C. (2010). Suffering, hope, and entrapment: resilience and cultural values in Afghanistan. Social Science and Medicine, 71(1), 71-83. [PubMed: 2045211]

Fraser, E., \& Pakenham, K. I. (2009). Resilience in children of parents with mental illness: relations between mental health literacy, social connectedness and coping, and both adjustment and caregiving. Psychology, Health and Medicine, 14(5), 573-584. [PubMed: 19844836] 


\section{Resilience in the Context of Informal Care giving: A Scoping Study}

Gaugler, J. E., Kane, R. L., \& Newcomer, R. (2007). Resilience and transitions from dementia caregiving. The Journals of Gerontology. Series B, Psychological Sciences and Social Sciences, 62(1), P38-44. [PubMed: 17284556]

Giesbrecht, M., Wolse, F., Crooks, V. A., \& Stajduhar, K. (2015). Identifying socioenvironmental factors that facilitate resilience among Canadian palliative family caregivers: a qualitative case study. Palliative and Supportive Care, 13(3), 555-565. [PubMed: 24477169]

Hall, H., Cote, J., McBean, A., \& Purden, M. (2012). The experiences of patients with pulmonary arterial hypertension receiving continuous intravenous infusion of epoprostenol (Flolan) and their support persons. Heart \& Lung, 41(1), 35-43. [PubMed: 21784527]

Harmell, A. L., Chattillion, E. A., Roepke, S. K., \& Mausbach, B. T. (2011). A review of the psychobiology of dementia caregiving: a focus on resilience factors. Current Psychiatry Reports, 13(3), 219-224. [PubMed: 21312008]

Heppenstall, C. P., Wilkinson, T. J., Hanger, H. C., Dhanak, M. R., \& Keeling, S. (2013). Impacts of the emergency mass evacuation of the elderly from residential care facilities after the 2011 Christchurch earthquake. Disaster Medicine and Public Health Preparedness, 7(4), 419-423. [PubMed: 24229527]

Hernandez, M., Barrio, C., \& Yamada, A. M. (2013). Hope and burden among Latino families of adults with schizophrenia. Family Process, 52(4), 697-708. [PubMed: 24329411]

House, L. A., Russell, H. F., Kelly, E. H., Gerson, A., \& Vogel, L. C. (2009). Rehabilitation and future participation of youth following spinal cord injury: caregiver perspectives. Spinal Cord, 47(12), 882-886. [PubMed: 19528994]

Kramer, B. J. (1997). Gain in the caregiving experience: where are we? What next? The Gerontologist, 37(2), 218-232. [PubMed: 9127978] Lamis, D. A., Wilson, C. K., Tarantino, N., Lansford, J. E., \& Kaslow, N. J. (2014). Neighborhood disorder, spiritual well-being, and parenting stress in African American women. Journal of Family Psychology: JFP: Journal of the Division of Family Psychology of the American
Psychological Association (Division 43), 28(6), 769-778. [PubMed: 24707802]

Lavretsky, H., Siddarth, P., \& Irwin, M. R. (2010). Improving depression and enhancing resilience in family dementia caregivers: a pilot randomized placebo-controlled trial of escitalopram. The American Journal of Geriatric Psychiatry, 18(2), 154. [PubMed: 20104071]

Leve, L. D., Fisher, P. A., \& Chamberlain, P. (2009). Multidimensional treatment foster care as a preventive intervention to promote resiliency among youth in the child welfare system. Journal of Personality, 77(6), 1869-1902. [PubMed: 19807861]

Lim, S., Zoellner, J. M., Ajrouch, K. J., \& Ismail, A. I. (2011). Overweight in childhood: the role of resilient parenting in African-American households. American Journal of Preventive Medicine, 40(3), 329-333. [PubMed: 21335265]

Lin, F. Y., Rong, J. R., \& Lee, T. Y. (2013). Resilience among caregivers of children with chronic conditions: a concept analysis. Journal of Multidisciplinary Healthcare, 6, 323-333. [PubMed: 24039436]

Luthar, S. S., Cicchetti, D., \& Becker, B. (2000). The construct of resilience: a critical evaluation and guidelines for future work. Child Development, 71(3), 543-562. [PubMed: 10953923]

McCubbin, H. I., \& Patterson, J. M. (1983). The family stress process: the double ABCX model of adjustment and adaptation. Marriage and Family Review, 6(1-2), 7-37.

McCubbin, M. A., \& McCubbin, H. I. (1993). Families coping with illness: the resiliency model of family stress, adjustment and adaptation. In C. B. Danielson, B. H. Bissell \& P. W. Fry (Eds.), Families, Health \& Illness: Perspectives on Coping and Intervention (pp. 21-63). St. Louis, MO: Mosby Year Book, Inc.

Merriam-Webster. (n. d.). Resilence. Retrieved January 20, 2016, from http://www.merriamwebster.com/dictionary/resilience

Morse, J. M. (1997). Considering theory derived from qualitative research. In J. M. Morse (Ed.), Completing a Qualitative Project (pp. 163-188). Thousand Oaks, CA: Sage.

Morse, J. M., \& Penrod, J. (1999). Linking concepts of enduring, uncertainty, suffering, and 
Medical Research Archives, Volume 4, Issue 6.

\section{Resilience in the Context of Informal Care giving: A Scoping Study}

hope. Image -The Journal of Nursing Scholarship, 31(2), 145-150. [PubMed: 10380390]

Nabors, L. A., Kichler, J. C., Brassell, A., Thakkar, S., Bartz, J., Pangallo, J., . . . Lundy, H. (2013). Factors related to caregiver state anxiety and coping with a child's chronic illness. Family Systems Health, 31(2), 171-180. [PubMed: 23795628]

Neill, J. T., \& Dias, K. L. (2001). Adventure education and resilience: a double-edged sword. Journal of Adventure Education and Outdoor Learning, 1, 35-42.

O'Dwyer, S., Moyle, W., \& van Wyk, S. (2013). Suicidal ideation and resilience in family carers of people with dementia: a pilot qualitative study. Aging \& Mental Health, 17(6), 753-760. [PubMed: 23611756]

O'Rourke, N., Kupferschmidt, A. L., Claxton, A., Smith, J. Z., Chappell, N., \& Beattie, B. L. (2010). Psychological resilience predicts depressive symptoms among spouses of persons with Alzheimer disease over time. Aging \& Mental Health, 14(8), 984-993. [PubMed: 21069604]

Patterson, J. M. (1988). Families experiencing stress: the family adapatation and response model. Family Systems Medicine, 5(2), 202-237.

Patterson, J. M. (2002). Integrating family resilience and family stress theory. Journal of Marriage and the Family, 64, 349-360.

Pearlin, L. I., \& Skaff, M. M. (1995). Stress and adaptation in late life Emerging Issues in Mental Health and Aging. Washington, DC: American Psychological Association.

Penrod, J., Baney, B. L., \& McGhan, G. E. (2012, September 13, 2012). Theoretical integration using methods of template comparison. Paper presented at the 2012 State of the Science Congress on Nursing Research, Washington, DC.

Penrod, J., Hupcey, J. E., Baney, B. L., \& Loeb, S. J. (2011). End-of-life caregiving trajectories. Clinical Nursing Research, 20(1), 7-24. [PubMed: 20876553]

Penrod, J., Hupcey, J. E., Shipley, P. Z., Loeb, S. J., \& Baney, B. (2012). A model of caregiving through the end of life: seeking normal. Western Journal of Nursing Research, 34(2):174-93. [PubMed: 21403056]
Polk, L. V. (1997). Toward a middle-range theory of resilience. ANS. Advances in Nursing Science, 19(3), 1-13. [PubMed: 9055026]

Richardson, G. E. (2002). The metatheory of resilience and resiliency. Journal of Clinical Psychology, 58(3), 307-321. [PubMed: 11836712]

Rolland, J. S., \& Walsh, F. (2006). Facilitating family resilience with childhood illness and disability. Current Opinions in Pediatrics, 18(5), 527-538. [PubMed: 16969168]

Rosenberg, A. R., Baker, K. S., Syrjala, K. L., Back, A. L., \& Wolfe, J. (2013). Promoting resilience among parents and caregivers of children with cancer. Journal of Palliative Medicine, 16(6), 645-652. [PubMed: 23646887]

Ruiz-Robledillo, N., De Andres-Garcia, S., PerezBlasco, J., Gonzalez-Bono, E., \& Moya-Albiol, L. (2014). Highly resilient coping entails better perceived health, high social support and low morning cortisol levels in parents of children with autism spectrum disorder. Research in Developmental Disabilities, 35(3), 686-695. [PubMed: 24405793]

Rutter, M. (2006). Implications of resilience concepts for scientific understanding. Annals of the New York Academy of Sciences, 1094, 1-12. [PubMed: 17347337]

Sandelowski, M. (2000). Combining qualitative and quantitative sampling, data collection, and analysis techniques in mixed-method studies. Research in Nursing \& Health, 23(3), 246-255. [PubMed: 10871540]

Sandler, I. N., Wolchik, S. A., Ayers, T. S., Tein, J. Y., \& Luecken, L. (2013). Family Bereavement Program (FBP) approach to promoting resilience following the death of a parent. Family Science, 4(1). [PubMed: 24273631]

Shin, S. H., Choi, H., Kim, M. J., \& Kim, Y. H. (2010). Comparing adolescents' adjustment and family resilience in divorced families depending on the types of primary caregiver. Journal of Clinical Nursing, 19(11-12), 1695-1706. [PubMed: 20345833]

Shuter, P., Beattie, E., \& Edwards, H. (2014). An exploratory study of grief and health-related quality of life for caregivers of people with dementia. American Journal of Alzheimer's Disease and 


\section{Resilience in the Context of Informal Care giving: A Scoping Study}

Other Dementias, 29(4), 379-385. [PubMed: 24381138]

Simpson, G., \& Jones, K. (2013). How important is resilience among family members supporting relatives with traumatic brain injury or spinal cord injury? Clinical Rehabilitation, 27(4), 367-377. [PubMed: 23012693]

Sinclair, V. G., \& Wallston, K. A. (2004). The development and psychometric evaluation of the Brief Resilient Coping Scale. Assessment, 11(1), 94-101. [PubMed: 14994958]

Smith, B. W., Dalen, J., Wiggins, K., Tooley, E., Christopher, P., \& Bernard, J. (2008). The brief resilience scale: assessing the ability to bounce back. Intertional Journal of Behavioral Medicine, 15(3), 194-200. [PubMed: 18696313]

Svanberg, E., Stott, J., \& Spector, A. (2010). 'Just helping': Children living with a parent with young onset dementia. Aging \& Mental Health, 14(6), 740-751. [PubMed: 20686983]

Turner, S. (2001). Resilience and social work practice: three case studies. Families in Society, 82(5), 441-450.

Wagnild, G. M., \& Collins, J. A. (2009). Assessing resilience. Journal of Psychosocial Nursing and Mental Health Services, 47(12), 28-33. [PubMed: 20000280]

Wagnild, G. M., \& Young, H. M. (1993). Development and psychometric evaluation of the Resilience Scale. Journal of Nursing Measurement, 1(2), 165-178. [PubMed: 7850498]

Wagnild, G., \& Young, H. M. (1990). Resilience among older women. Image -The Journal of Nursing Scholarship, 22(4), 252-255. [PubMed: 2292448]

Walsh, F. (2003). Family resilience: a framework for clinical practice. Family Process, 42(1), 1-18. [PubMed: 12698595]

Wilks, S. E. (2008a). Psychometric evaluation of the shortened resilience scale among Alzheimer's caregivers. American Journal of Alzheimer's Disease and Other Demenentias, 23(2), 143-149. [PubMed: 18198238]
Wilks, S. E. (2008b). Psychometric evaluation of the shortened resilience scale among Alzheimer's caregivers. American Journal of Alzheimer's Disease and Other Demenentias, 23(2), 143-149. [PubMed: 18198238]

Wilks, S. E., \& Croom, B. (2008). Perceived stress and resilience in Alzheimer's disease caregivers: testing moderation and mediation models of social support. Aging \& Mental Health, 12(3), 357-365. [PubMed: 18728949]

Wilks, S. E., Little, K. G., Gough, H. R., \& Spurlock, W. J. (2011). Alzheimer's aggression: influences on caregiver coping and resilience. Journal of Gerontological Social Work, 54(3), 260275. [PubMed: 21462058]

Wilks, S. E., \& Vonk, M. E. (2008). Private prayer among Alzheimer's caregivers: mediating burden and resiliency. Journal of Gerontological Social Work, 50(3-4), 113-131.[PubMed: 18510194]

Yeh, P. M., \& Bull, M. (2012). Use of the resiliency model of family stress, adjustment and adaptation in the analys is of family caregiver reaction among families of older people with congestive heart failure. International Journal of Older People Nursing, 7(2), 117-126. [PubMed: 21631886]

Zauszniewski, J. A., Bekhet, A. K., \& Suresky, M. J. (2009). Effects on resilience of women family caregivers of adults with serious mental illness: the role of positive cognitions. Archives of Psychiatric Nursing, 23(6), 412-422. [PubMed: 19926023]

Zauszniewski, J. A., Bekhet, A. K., \& Suresky, M. J. (2010). Resilience in family members of persons with serious mental illness. The Nursing Clinics of North America, 45(4), 613-626, vii. [PubMed: 20971340]

Zhang, B., El-Jawahri, A., \& Prigerson, H. G. (2006). Update on bereavement research: evidencebased guide lines for the diagnosis and treatment of complicated bereavement. Journal of Palliative Medicine, 9(5), 1188-1203. [PubMed:

17040157] 
Medical Research Archives, Volume 4, Issue 6.

\section{Resilience in the Context of Informal Care giving: A Scoping Study}

\section{Table I. Key Purpose of the 41 Included Studies}

\begin{tabular}{|c|c|c|c|}
\hline Author, date, country & Purpose of the study & Author/date/country & Purpose of the study \\
\hline Amzel, 2013, USA & $\begin{array}{l}\text { Discusses using adaptations of psychosocial support } \\
\text { interventions for HIV-positive children in resource- } \\
\text { limited settings }\end{array}$ & Eggerman, 2010, UK & $\begin{array}{l}\text { To examine resilience in children and adults } \\
\text { facing adversity in war-affected areas of } \\
\text { Afghanistan }\end{array}$ \\
\hline Bayat, 2007, USA & $\begin{array}{l}\text { To examine factors of resilience in families of children } \\
\text { with autism }\end{array}$ & Fraser, 2009, Australia & $\begin{array}{l}\text { To examine resilience in children of parents } \\
\text { with mental illness }\end{array}$ \\
\hline Bekhet, 2012, USA & $\begin{array}{l}\text { To examine the potential effects of positive cognitions on } \\
\text { the relationship between caregiver burden and } \\
\text { resourcefulness, among caregivers of persons with } \\
\text { autistic spectrum disorder }\end{array}$ & Gaugler, 2007, USA & $\begin{array}{l}\text { To examine resilience in long term dementia } \\
\text { caregiving }\end{array}$ \\
\hline Bonanno, 2005, USA & To examine resilience in loss of spouse, parent, or partner & $\begin{array}{l}\text { Giesbrecht, } 2013, \\
\text { Canada }\end{array}$ & $\begin{array}{l}\text { To examine resilience and empowerment in } \\
\text { Canadian palliative family caregivers }\end{array}$ \\
\hline Bull, 2014, USA & $\begin{array}{l}\text { To describe caregivers' resilience and psychological } \\
\text { distress strategies in caring for an older adults with } \\
\text { dementia }\end{array}$ & Haley, 2009, USA & $\begin{array}{l}\text { To examine long-term effects of bereavement } \\
\text { on dementia caregivers }\end{array}$ \\
\hline Cassidy, 2012, UK & $\begin{array}{l}\text { To explore benefit finding in the experience of cancer } \\
\text { caregivers and to test the model of benefit finding }\end{array}$ & Hall, 2012, Canada & $\begin{array}{l}\text { To examine the experiences of patients with } \\
\text { pulmonary arterial hypertension receiving } \\
\text { continuous intravenous infusion of } \\
\text { epoprostenol and their support persons }\end{array}$ \\
\hline Cassidy, 2013, UK & $\begin{array}{l}\text { To incorporate and test measures of resilience and benefit } \\
\text { finding within a stress-coping model of the young carer } \\
\text { experience }\end{array}$ & Harmell,2011, USA & $\begin{array}{l}\text { To review psychobiology of resilience factors } \\
\text { in dementia caregiving }\end{array}$ \\
\hline Chappell, 2008, Canada & $\begin{array}{l}\text { To examine predictors of caregiver burden and quality of } \\
\text { life among caregivers experiencing heavy care demand in } \\
\text { Vancouver Island }\end{array}$ & $\begin{array}{l}\text { Heppenstall, } \\
\text { New Zealand }\end{array}$ & $\begin{array}{l}\text { To assess the impact of natural disaster events } \\
\text { on frail older adults more closely for future } \\
\text { preparedness }\end{array}$ \\
\hline
\end{tabular}


Medical Research Archives, Volume 4, Issue 6.

\section{Resilience in the Context of Informal Care giving: A Scoping Study}

\begin{tabular}{|c|c|c|c|}
\hline Chen, 2008, Taiwan & $\begin{array}{l}\text { To explore family carers' experiences of taking care of } \\
\text { relatives with spinal cord injuries }\end{array}$ & Hernandez, 2013, USA & $\begin{array}{l}\text { To examine the relationship between hope and } \\
\text { burden of care among Latino families with } \\
\text { schizophrenia }\end{array}$ \\
\hline House, 2009, USA & $\begin{array}{l}\text { To examine caregivers' perspectives on the effectiveness } \\
\text { of rehabilitative support experienced by youth with spinal } \\
\text { cord injury }\end{array}$ & Shin, 2010, USA & $\begin{array}{l}\text { To examine adolescent adjustment and family } \\
\text { resilience in divorced families }\end{array}$ \\
\hline Lamis, 2014, USA & $\begin{array}{l}\text { To examine neighborhood disorder, spiritual well-being } \\
\text { and parenting stress in mothers of African American } \\
\text { children }\end{array}$ & Shuter, 2014, Australia & $\begin{array}{l}\text { To explore grief and health related quality of } \\
\text { life for caregivers of people with dementia }\end{array}$ \\
\hline Lavretsky, (2010), USA & $\begin{array}{l}\text { To examine potential of an antidepressant drug to } \\
\text { improve depression, resilience to stress, and quality of } \\
\text { life in family dementia caregivers }\end{array}$ & Simpson, 2012, Australia & $\begin{array}{l}\text { To investigate resilience among family } \\
\text { members supporting relatives with traumatic } \\
\text { brain or spinal cord injury }\end{array}$ \\
\hline Leve, 2009, USA & $\begin{array}{l}\text { To describe resilience among youth in the child welfare } \\
\text { system }\end{array}$ & Svanberg, 2010, UK & $\begin{array}{l}\text { To examine resilience of young children } \\
\text { caring for parents with dementia }\end{array}$ \\
\hline Lim, 2011, USA & $\begin{array}{l}\text { To examine the relationship between healthy weight } \\
\text { maintenance and dietary compliance and resilient } \\
\text { parenting in African American households }\end{array}$ & Wilks, 2008, USA & $\begin{array}{l}\text { To examine caregiver adaptational success } \\
\text { through a psychometric analysis of a modified } \\
\text { version of a popular resilience measure among } \\
\text { informal Alzheimer's caregivers }\end{array}$ \\
\hline 20/Lin, 2013, China & $\begin{array}{l}\text { To clarify the meaning of resilience in terms of } \\
\text { caregivers who care for children with chronic conditions }\end{array}$ & Wilks, 2008, USA & $\begin{array}{l}\text { To examine social support and perceived } \\
\text { stress and resilience in caregivers of } \\
\text { Alzheimer's patients }\end{array}$ \\
\hline Nabors, 2013, USA & $\begin{array}{l}\text { To examine caregiver views of factors related to coping } \\
\text { in children w ith various chronic illnesses }\end{array}$ & Wilks, 2011, USA & $\begin{array}{l}\text { To understand whether Alzheimer's } \\
\text { aggression impacts caregiving coping } \\
\text { strategies and ability to manage adversity }\end{array}$ \\
\hline O'Dwyer, 2013, Australia & $\begin{array}{l}\text { To explore suicide risk and resilience in family caregivers } \\
\text { of people with dementia }\end{array}$ & Yeh, 2011, USA & $\begin{array}{l}\text { To examine the influences } \\
\text { of older people's activities } \\
\text { of daily living dependency, family caregivers' } \\
\text { spiritual well-being, quality of relationship, } \\
\text { family support, coping and care continuity on } \\
\text { the burden of family caregivers of } \\
\text { hospitalized patients with CHF }\end{array}$ \\
\hline O’Rourke, 2010, Canada & $\begin{array}{l}\text { To examine whether resilience predicts depressive } \\
\text { symptoms in spouses of Alzheimer's patients }\end{array}$ & $\begin{array}{l}\text { Zauszniewski, } \\
\text { USA }\end{array}$ & $\begin{array}{l}\text { To examine the effects of risk and protective } \\
\text { factors on resilience on women family } \\
\text { members of adults with serious mental illness }\end{array}$ \\
\hline
\end{tabular}


Medical Research Archives, Volume 4, Issue 6.

\section{Resilience in the Context of Informal Care giving: A Scoping Study}

\begin{tabular}{|l|l|l|l|}
\hline Rosenberg, 2013, USA & $\begin{array}{l}\text { To review the resilience literature in pediatric cancer } \\
\text { settings and develop an integrative framework of fixed } \\
\text { and mutable factors of resilience }\end{array}$ & $\begin{array}{l}\text { Zauszniewski, } \\
\text { USA }\end{array}$ & $\begin{array}{l}\text { 2010, examine the effects of risk and protective } \\
\text { factors on resilience family members of } \\
\text { persons with serious mental illness }\end{array}$ \\
\hline $\begin{array}{l}\text { Ruiz-Robledillo, 2013, } \\
\text { Spain }\end{array}$ & $\begin{array}{l}\text { To evaluate the association between resilience and health } \\
\text { outcomes in parents with autism spectrum disorder }\end{array}$ & $\begin{array}{l}\text { To update research on resilience in } \\
\text { bereavement }\end{array}$ & \\
\hline Sandler, 2013, USA & $\begin{array}{l}\text { To describe a resilience model used in a family } \\
\text { bereavement program following death of a parent }\end{array}$ & & \\
\hline
\end{tabular}


Medical Research Archives, Volume 4, Issue 6.

\section{Resilience in the Context of Informal Care giving: A Scoping Study}

Table II. Targe ted Disciplines (Determined by the Focus of Journal Readership).

\begin{tabular}{lc}
\hline Disciplinary Perspective & Number (\% Total Sample) \\
\hline Multidisciplinary & $24(60)$ \\
Gerontology & 7 \\
Palliative care & 3 \\
Family & 3 \\
Alzheimer's and other dementias & 2 \\
Rehabilitation & 2 \\
Preventive medicine & 1 \\
Social science & 1 \\
Healthcare & 1 \\
Cardio vascular & 1 \\
Spinal cord injury & 1 \\
AIDS & 1 \\
Intellectual disability & 1 \\
Psychology/psychiatry & $8(20)$ \\
General focus & 6 \\
Family & 1 \\
Geriatrics & 1 \\
Nursing & $7(17.5)$ \\
General focus & 4 \\
Psychiatric/mental health & 2 \\
Care of older adults & 1 \\
Social work & $1(2.5)$ \\
Gerontology & 1 \\
Total & 40 \\
\hline
\end{tabular}


Medical Research Archives, Volume 4, Issue 6.

\section{Resilience in the Context of Informal Care giving: A Scoping Study}

Table III. Caregiving Context

\begin{tabular}{|c|c|}
\hline Caregiving Context & Number (\% Total Sample) \\
\hline Health conditions & $31(76)$ \\
\hline Dementia & 7 \\
\hline Alzheimer disease & 4 \\
\hline Mental illness & 3 \\
\hline Autism spectrum disorder & 3 \\
\hline Traumatic brain or spinal cord injury & 3 \\
\hline Life limiting/advanced chronic illness & 3 \\
\hline Chronic illness & 2 \\
\hline Schizophrenia & 1 \\
\hline Mixed chronic illness/disability & 1 \\
\hline Pulmonary arterial hypertension & 1 \\
\hline Congestive heart failure & 1 \\
\hline Unspecified; older adults requiring $\geq$ four hours direct care/day & 1 \\
\hline AIDS & 1 \\
\hline Socia1/economic influences & $5(12)$ \\
\hline Parenting in low social economic status & 3 \\
\hline Divorce & 1 \\
\hline War-affected area & 1 \\
\hline Post caregiving & $5(12)$ \\
\hline Bereavement & 5 \\
\hline Total & $41 *$ \\
\hline
\end{tabular}

*One article reports two discrete studies, therefore the total number of studies exceeds the number of articles in the sample $(\mathrm{N}=40)$ 
Medical Research Archives, Volume 4, Issue 6.

Resilience in the Context of Informal Care giving: A Scoping Study

Table IV. Caregiver/Care Recipient Relationship. Number of Caregive rs*

\begin{tabular}{lc}
\hline Caregiver Relationship to Care Recipient & Number (\%) \\
\hline Parent & $2141(28.5)$ \\
Spouse & $2365(31.4)$ \\
Sibling & $197(2.6)$ \\
Children & $1068(14.2)$ \\
Other (e.g., grandparents, grandchild, friend) & $172(2.3)$ \\
Unknown & $1582(21.2)$ \\
Total & $7525(100.0)$ \\
\hline
\end{tabular}

$*(\mathrm{~N}=7525)$ 